\title{
Mesleksel nikel dermatiti
}

\author{
Occupational nickel dermatitis
}

\author{
Aslı AYTEKİN, Hınç YILMAZ
}

\section{ÖZET}

Endüstriyel toplumlarda tüm meslek hastalıklarının \%30'unu mesleki deri hastalıkları oluşturur. Epidemiyolojik verilere göre kontakt dermatitler mesleki deri hastalıklarının önemli bir kısmını oluşturmaktadır. Metaller en yaygın kontakt allerjenler olup, nikel metal allerjilerinin en yaygın nedenidir. Kadınlarda nikel duyarlılığı başta küpe olmak üzere takı ve benzeri aksesuarlarla ilişkilidir. Küpe başta olmak üzere her türlü takı, giysilerin ve çamaşırların metal kopçaları, düğme ve tokaları, madeni paralar, anahtarlar, gözlük çerçeveleri ve daha çok çeşitli ürün nikel içermektedir. Erkeklerde nikel duyarlılığ kazanılmaktadır. Yapılan çalışmalar göstermiştir ki; endüstride pek çok meslek grubunda nikele maruziyet söz konusudur. Bunlar arasında alkali pil yapımı, çinko ve pirinç karartma, elektrolizle kaplama, lehimleme, elektrik kablo işleri sayılabilir. Nikel dermatiti kuaförlerde, müzisyenlerde ve terzilerde de ortaya çıkabilmektedir. Nikel dermatitinin besinlerle alınan nikel ile de ilişkili olduğu ortaya konulmuştur. Sigara içenlerde içmeyenlere oranla daha yüksek nikel duyarlılığ tespitinde esas olarak yama testleri kullanılmaktadır. Nikel dermatitinden korunmada nikel maruziyetinin azaltılması esastır. $\mathrm{Bu}$ yazıda, nikel dermatitinin daha sık görüldügü meslek grupları ile tanı ve korunmada dikkat edilmesi gereken noktalar literatür bilgileri 1şı̆̆ında gözden geçirilmektedir.

Anahtar kelimeler: Meslek hastalıkları, Nikel, Dermatit

Aslı Aytekin (囚)

Dermatoloji, Ankara Meslek Hastalıkları Hastanesi, Ankara, Türkiye

e-mail: asliteo@gmail.com

Hınç Yılmaz

Toksikoloji, Ankara Meslek Hastalıkları Hastanesi, Ankara, Türkiye

\begin{abstract}
Thirty percent of all occupational diseases in industrial societies are occupational skin diseases. An important part of occupational skin diseases is contact dermatitis with respect to epidemiological data. Metals are the most common contact allergens and nickel is the most common among them. Nickel sensitivity in women is particularly related to jewelry, including earrings and other accessories. Especially all kinds of earrings, apparels and their metal clasps, buttons and buckles, coins, keys, frames of glasses and many more different kinds of products contain nickel. Nickel sensitivity in men is primarily occupational. Previous studies have shown that occupational exposure to nickel is seen in many industrial groups including alkaline battery manufacturing, zinc and brass dimming, electroplated coating, welding and electrical wiring. Nickel dermatitis may also occur in hairdressers, musicians and tailors. Nickel dermatitis was found to be associated with dietary nickel. Nickel sensitivity has been determined as higher in smokers than in non-smokers. Patch tests are mainly used for the diagnosis of nickel sensitivity. Reducing nickel exposure is essential for prevention of nickel dermatitis. In this paper, in the light of the literature, occupational groups more prone to nickel dermatitis and diagnosis and prevention of nickel dermatitis are reviewed.
\end{abstract}

Key words: Occupational diseases, Nickel, Dermatitis

\section{Giriş}

Mesleksel hastalıklar, bir mesleğin uygulanması sırasında kimyasal, mekanik, fiziksel ve biyolojik faktörlerin etkisi ile meydana gelen hastalıklardır. Endüstriyel toplumlarda tüm meslek hastalıklarının \%30'unu mesleksel deri hastalıkları oluşturur. Sık tekrar etmeleri, iş gücü kayıpları ve iş değişikliklerine neden olmaları yüzünden önemli bir halk sağlığı sorunu oluşturmaktadırlar. Mesleksel kontakt dermatitler tüm mesleki deri hastalıklarının \%90-95'ini oluşturur. Mesleksel kontakt dermatitlerin \%70-80'ninden irritan kontakt dermatitler, \%20-25'inden alerjik kontakt dermatitler sorumludur [1,2]. Metaller en yaygın kontakt allerjenlerdir. Altın, krom, kobalt ve civanın organik tuzlarına karşı reaksiyonlar oldukça sık görülmesine rağmen pek çok seride nikel, metal allerjilerinin en yaygın nedenidir 
[3-6]. Genel popülasyonda nikele bağlı allerjik kontakt dermatit prevalansı $\% 4,5$ ile $\% 8,6$ arasında değişmektedir [7]. Kuzey Amerika Kontakt Dermatit Grubu'nun 2007 ve 2008 yıllarında yapılmış deri yama testlerinin sonuçlarını değerlendirdikleri çalışmalarında nikel en sık rastlanan allerjen olarak tespit edilmiştir [8].

Nikel çok eski çağlardan beri bilinen, periyodik cetvelde geçiş metalleri arasında bulunan, 28 atom numaralı, kimyada sembolü "Ni" olan bir elementtir. Gümüş beyaz renkli, dövülebilen, 1sıtıldığında kırılmadan uzayabilen oldukça sert bir metaldir. Doğada sülfür ve silika yataklarında diğer metallerle, en çok kobalt ile birlikte bulunur. Sülfür cevherlerinin pirometalurjik yöntemlerle zenginleştirilmesi ile saf nikel elde edilir. Saf nikel, sağlam, sert, paslanmaz, hava ve kimyasal değişimlerden etkilenmeyen bir maddedir. Bu özelliği yüzünden birçok alaşım türünün yapımında aranan bir elemandır.

Nikel manyetik alana sahiptir ve bu özelliğini 360 dereceye kadar korur. İlave edildiği metalin özelliklerini kuvvetlendirebilir, bu nedenle 3000 kadar alaşımın bünyesine girer. Alaşımlar içinde sanayide en çok kullanılanı paslanmaz çeliktir. Saf nikel özellikle kaplamacılıkta kullanılır. Bu işleme nikelaj denir. Ayrıca nikel oksit halinde iken seramik sanayinde renk verici olarak kullanılır [9].

\section{Nikel Maruziyeti}

Günlük yaşamda nikel içeren pek çok madde ile karşılaşılmaktadır. Küpe başta olmak üzere her türlü tak1, giysilerin ve çamaşırların metal kopçaları, metal düğme ve

Tablo I. Nikele sık olarak maruz kalan meslek grupları.

\begin{tabular}{|c|c|}
\hline Meslek Grubu & Nikel Maruziyeti Nedeni \\
\hline $\begin{array}{l}\text { Kimyasal } \\
\text { maddelerle temas } \\
\text { eden işçiler }\end{array}$ & $\begin{array}{l}\text { Alkali piller (nikel-kadmiyum), plastikler, } \\
\text { seramikler, boya sabitleyicileri, yağ } \\
\text { sertleştiriciler, böcek ilaçları, resim ve duvar } \\
\text { kağıdı renklendiricileri }\end{array}$ \\
\hline $\begin{array}{l}\text { Paslanmaz çelik } \\
\text { fabrikası çalışanları }\end{array}$ & $\begin{array}{l}\text { Çinko ve pirinç kaplama malzemeleri, } \\
\text { lehimleme maddeleri, boyalar, metal plaka, } \\
\text { kesme, boyama, sertleştirme ve kaplama } \\
\text { solüsyonları }\end{array}$ \\
\hline Kuaförler & $\begin{array}{l}\text { Kalıcı perma solüsyonları, saç boyaları, ruj, } \\
\text { far, göz kalemi gibi kozmetikler }\end{array}$ \\
\hline $\begin{array}{l}\text { Elektronik } \\
\text { çalışanları }\end{array}$ & $\begin{array}{l}\text { Statik elektriği dağıtmak için kullanılan } \\
\text { nikel içeren metal bantlar }\end{array}$ \\
\hline Kasiyerler & Madeni paralar \\
\hline $\begin{array}{l}\text { Yemek sektörü } \\
\text { çalışanları }\end{array}$ & Nikel içeren gıdalar \\
\hline $\begin{array}{l}\text { Madenciler, rafineri } \\
\text { çalışanları }\end{array}$ & $\begin{array}{l}\text { Elektroliz sırasında ortaya çıkan nikel } \\
\text { karbonil solüsyonları ve gazları }\end{array}$ \\
\hline
\end{tabular}

tokalar, madeni paralar, anahtarlar, gözlük çerçeveleri, saat kayışları, fermuar, bisiklet gidonu, kapı kolları, kontakt lens temizleme solüsyonları, epilasyon iğneleri, göz kalemi ve farlar, ruj, saç tokaları, çeşitli mutfak malzemeleri, pantolon metal askıları, mücevherler ve daha çok çeşitli ürün nikel içermektedir [10].

Nikel ile gündelik hayatta çok sık karşılaşılması ve sık alerjiye neden olması nedeni ile nikel içeren ürünlerin kullanımında bazı standartlar geliştirilmiştir. Avrupa Birliği 2004 yılında tak1, mücevher, saat ve giyim eşyası aksesuarları gibi vücutla temas eden nikelden yapılan ürünlerin kullanımına yönelik bir yönetmelik hazırlamıştır (The European Directive Restricting the Use of Nickel Commision Directive 2004/96/EC of 27 September 2004). $\mathrm{Bu}$ yönetmeliğe göre nikelle kaplanmış veya nikel içeren objelerin sağlaması gereken kriterler üç maddede özetlenmiştir;

1- Deriyi delici işlemler ile uygulanan nikel içeren objelerde (örneğin; kulağı delerek takılan küpeler ve diğer vücut "piercing”lerinde) nikel salınım oranının 0,2 mikrogram/cm2/haftayı geçmemesi

2- Deriye direk ve/veya uzun süreli temas edecek şekilde kullanılacak nikel içeren objelerde (kulak küpeleri, kolye, zincir, halhal, yüzük, kol saatleri, kasa, kayış, kordon ve vidaları, elbiselerde kullanılacak baskı düğme, kopça, fermuarlar ve metal markalar) nikel salınım oranının 0,5 mikrogram $/ \mathrm{cm}^{2} /$ haftayı geçmemesi

3- Nikelden yapılmış ancak nikel içermeyen kaplama maddesi ile kaplanmış objelerde en az 2 yıl boyunca nikel salınım oranının 0,5 mikrogram $/ \mathrm{cm}^{2} /$ haftayı geçmemesi

Nikel besinlerde yaygın olarak bulunmaktadır. Nikelin yiyeceklerdeki kaynağı olarak; tuz (5-500 $\mu \mathrm{gr} / \mathrm{gr})$, bitkisel ürünler $(0,5-5 \mu \mathrm{gr} / \mathrm{gr})$, hayvansal ürünler $(0,1-5 \mu \mathrm{gr} / \mathrm{gr})$ ve su $(5-100 \mu \mathrm{gr} / \mathrm{l})$ sayllabilir. Paslanmaz çelik tencerede pişen asitli yiyecekler, istiridye, kakao ve çikolata, fasulye, 1spanak, bezelye, jelatin, fındık, ceviz, yulaf, buğday, çavdar, domates, balık ve konserve gıdalar gibi çeşitli besinler yüksek oranda nikel içermektedir [11].

Çalışma hayatında da en sık karşılaşılan metallerden birisi nikeldir [12,13]. Alkali piller, çinko ve pirinç kaplama malzemeleri, seramikler, elektrolizle kaplama ve lehimleme maddeleri, boyalar, elektrik kabloları, emayeler, yakıt katkı maddeleri, yă sertleştiriciler, böcek ilaçları, boya sabitleyiciler, nikel alaşımlar, cam boyama malzemeleri, resim ve duvar kağıdı renklendiricileri, plastikler nikel içeren endüstriyel ürünlerdir. Nikel maruziyeti riski yüksek olan meslek grupları Tablo I'de belirtilmiştir. Bu meslek gruplarında duyarlanma daha sık olacağ 1 için nikele bağlı dermatit gelişimi de daha fazla beklenmektedir Ayrıca literatürde diş teknisyenleri, müzisyenler, marangozlar gibi meslek gruplarında da temas ettikleri nikel içeren maddelere 
Tablo II. Mesleksel kontakt dermatit ile nikel ilişkisini gösteren çalışmalar

\begin{tabular}{|c|c|c|c|c|}
\hline Çalışma & Meslekler & $\begin{array}{l}\text { Hasta } \\
\text { say1s1 }\end{array}$ & $\begin{array}{l}\text { Mesleksel } \\
\text { kontakt } \\
\text { dermatit } \\
\text { siklığ } 1\end{array}$ & $\begin{array}{l}\text { Yama } \\
\text { testinde } \\
\text { en sik } \\
\text { allerjen }\end{array}$ \\
\hline $\begin{array}{l}\text { Wallenhammer ve } \\
\text { ark. [15] İsveç (2000) }\end{array}$ & Diş hekimi & 3500 & $\% 14,9$ & Nikel \\
\hline $\begin{array}{l}\text { Duarte ve } \\
\text { ark. [16] } \\
\text { Brezilya (2010) }\end{array}$ & $\begin{array}{l}\text { Ev } \\
\text { temizlikçileri, } \\
\text { Kuaförler, } \\
\text { İnşaat işçileri, } \\
\text { Marangozlar, } \\
\text { Aşçı, } \\
\text { Kimyager }\end{array}$ & 630 & $\% 7,6$ & $\begin{array}{l}\text { Nikel } \\
(\% 23)\end{array}$ \\
\hline $\begin{array}{l}\text { Shiao ve ark. [18] } \\
\text { Tayvan (2004) }\end{array}$ & $\begin{array}{l}\text { Elektronik } \\
\text { işçileri }\end{array}$ & 3070 & $\% 9,8$ & Nikel \\
\hline $\begin{array}{l}\text { Kreicsz ve ark. [19] } \\
\text { Polonya (2011) }\end{array}$ & Kuaförler & 139 & $\% 43,9$ & $\begin{array}{l}\text { Nikel } \\
(\% 29,3)\end{array}$ \\
\hline $\begin{array}{l}\text { Bordel-Gomez ve ark. } \\
\text { [20] İspanya (2010) }\end{array}$ & $\begin{array}{l}\text { Metal işçileri, } \\
\text { İnşaat işçileri, } \\
\text { Kuaförler }\end{array}$ & 1092 & $\% 21,3$ & $\begin{array}{l}\text { Nikel } \\
(\% 29,3)\end{array}$ \\
\hline
\end{tabular}

bağlı mesleksel nikel dermatiti tespit edildiğini gösteren çalışmalar mevcuttur [14-16].

\section{Nikele duyarlanma ve nikel maruziyetinin tespiti}

Nikele duyarlanmada kadınlarda en sık neden kulak deldirmedir [17]. Takılar, elbise aksesuarları ve çamaşır kopçalarında bulunan nikele direk temas da bir diğer duyarlanma nedenidir. Erkeklerde ise nikele duyarlanma kadınlardan farklı olarak daha çok mesleksel kökenlidir $[15,16,18-20]$. Literatürde değişik meslek gruplarında mesleksel kontakt dermatitin etyolojisine yönelik pek çok çalışmada yama testleri sonuçlarında en sık saptanan allerjenin nikel olduğu görülmektedir (Tablo II). Erkeklerde mesleksel olmayan duyarlanma en sik kol saatleri, kot pantolon düğmeleri, kemer tokaları ile oluşmaktadır. Son yıllarda vücut "piercing” i yaptıran erkeklerde artış olması mesleksel olmayan nikel dermatitinde de artışa yol açmaktadır [9]. Ayrıca cep telefonlarının gündelik yaşamda yaygın olarak kullanılmaya başlanmasından sonra, hem kadınlarda hem de erkeklerde, özellikle yanak bölgesine lokalize kontakt dermatit olgularıyla karşılaşılmaktadır [21].

Yaşam biçiminin nikel duyarlılığına etkisini araştıran bir çalışmada, sigara içenlerde içmeyenlere oranla daha yüksek nikel duyarlılığı tespit edilmiştir. Bunun tütün bitkisinin topraktan, gübrelerden veya tarım ilaçlarından absorbe ettiği nikelden kaynaklandığ1 düşünülmektedir. Aynı çalışmada alkol tüketiminin kontakt duyarlılığı arttırmada herhangi bir etkisinin olmadığı gösterilmiştir [22].

Nikel duyarlanmasının saptanmasında yama testleri önemli bir yere sahiptir. Standart yama test serileri; sayıları 20-25 arasında değişen en önemli kontakt duyarlandırıcıların bir araya getirilmesi ile oluşturulmuştur. Halen birbirinden bağımsız çalışan 3 majör grup tarafından önerilen 3 ayrı standart seri mevcuttur; Avrupa standart serisi, Amerika standart serisi ve Japon standart serisi. Avrupa ülkeleri gibi bizim ülkemizde de Uluslararası Kontakt Dermatit Araştırma Grubu ile Avrupa Çevre ve Kontakt Dermatit Araştırma Grubunun ortak işbirliği ile oluşturulan Avrupa standart yama testi serisi kullanılmaktadır. Avrupa standart serisi 23 alerjen içermektedir ve nikel "\%5 nikel sülfat" olarak vazelin içinde test edilmektedir. Bu konsantrasyonda pozitif reaksiyon oranı yüksek, irritasyon oranı düşüktür [23]. Ancak vazelin içinde nikelin çok iyi dağılamadığı durumlarda yalancı negatif sonuçlar görülebilmektedir. Son yıllarda nikel klorit, jel içinde daha iyi dağıldı ğından, Thin-Layer Rapid Use Epicutaneous (T.R.U.E.) testlerin vazelin-nikel sülfat içeren testlere göre daha doğru sonuçlar verdiği bildirilmektedir [9]. Nikel doğada birçok metalle bir arada bulunduğundan nikel allerjisi ile birlikte kobalt, bakır ve paladium gibi metallerin allerjilerine de rastlanmaktadır. Nikel periferik kanda mononükleer hücrelerde T-yardımcı-1 ve T-yard1mc1-2 tipi sitokinlerin in vitro üretimini arttırmaktadır. Hücresel immün cevapta meydana gelen bu değişiklikler başka bir metale karşı allerjik reaksiyonu da arttırmaktadır [24]. Yama testi sonuçlarına göre popülasyonda nikel duyarlılı̆ 1 \% 6-30 arasında değişmektedir. Kadınlarda erkeklere oranla 2-10 kat daha sik görülmektedir [25,26]. Japonya'da yapılan ve son 19 yılın verilerini inceleyen bir çalışmada tekrarlayan kontakt dermatiti olup da metal yama testi uygulanan hastalarda cinsiyet ve yaş farkı gözetmeksizin en sik allerjiye yol açan metalin nikel olduğu tespit edilmiştir [27]. Ülkemizde yapılan çalışmalarda da yama testlerinde en s1k tespit edilen allerjenin nikel olduğunu gösteren bulgular mevcuttur (Tablo III) [28-31]. Nikelle

Tablo III. Ülkemizde yapılmış çalışmalarda yama testi sonuçları ile nikel alerjisi sıklığ

\begin{tabular}{|c|c|c|c|c|}
\hline Çalışma & $\begin{array}{l}\text { Çalışma } \\
\text { tarihi }\end{array}$ & $\begin{array}{l}\text { Çalışma } \\
\text { merkezi }\end{array}$ & $\begin{array}{l}\text { Hasta } \\
\text { Sayıs1 }\end{array}$ & $\begin{array}{l}\text { Nikel sülfat } \\
\text { allerjisi sıklığ } 1\end{array}$ \\
\hline $\begin{array}{l}\text { Akyol ve ark. } \\
\text { [28] (1996) }\end{array}$ & 1992-1995 & $\begin{array}{l}\text { Ankara } \\
\text { Üniversitesi } \\
\text { T1p Fakültesi }\end{array}$ & 318 & $\% 13,5$ \\
\hline $\begin{array}{l}\text { Akasya- } \\
\text { Hillenbrand ve } \\
\text { ark. [29] (2002) }\end{array}$ & 1996-1997 & $\begin{array}{l}\text { İstanbul } \\
\text { Üniversitesi } \\
\text { T1p Fakültesi }\end{array}$ & 542 & $\% 19,1$ \\
\hline Ada [30] (2010) & 1997-2009 & $\begin{array}{l}\text { Başkent } \\
\text { Üniversitesi } \\
\text { Tıp Fakültesi }\end{array}$ & 775 & $\% 17,3$ \\
\hline $\begin{array}{l}\text { Gündüz ve ark. } \\
\text { [31] (2011) }\end{array}$ & 2009-2010 & $\begin{array}{l}\text { Ankara } \\
\text { Meslek } \\
\text { Hastalıkları } \\
\text { Hastanesi }\end{array}$ & 231 & $\% 26,6$ \\
\hline
\end{tabular}


Tablo-IV. Mathias Kriterleri [34]

\begin{tabular}{l}
\hline 1-Klinik görünüm kontakt dermatit ile uyumlu mu? \\
2-Muhtemel irritan veya allerjen maddeler ile iş yerinde temas var \\
mı? \\
3-Lezyonların anatomik dağılımı mesleksel maruziyet ile uyumlu mu? \\
4-Kontakt dermatitin başlangıcı ile maruziyet arasında zamansal \\
olarak ilişki var mı? \\
5-Mesleki olmayan maruziyetler dışlandı mı? \\
6-Şüpheli irritan ve/veya alerjene maruz kalınan işten uzak- \\
laştırıldığında dermatit düzeliyor mu? \\
7-Yama veya provakasyon testleri ile olası bir alerjik neden saptanmış \\
mı?
\end{tabular}

teması tespit etmek için kullanılan yöntemlerden biri Shore ve arkadaşları tarafından modifiye edilen dimetilglioksim testidir [32]. Metal objelerde mevcut olan nikeli veya haftada $0,5 \mu \mathrm{gr} / \mathrm{cm}^{2}$ nikel salıveren maddelerdeki nikeli tespit etmeye yarayan pratik bir testtir. Alkol içinde $\% 1$ dimetilglioksim solüsyonu ve $\% 10$ amonyum hidroksit içeren kit solüsyonu pamuk uçlu çubuk aplikatörün ucuna bir kaç damla dökülür. Daha sonra aplikatör test objesine sürülür. Aplikatörün ucunda oluşan kırmızı renk test edilen objede serbest nikel bulunduğunu gösterir.

Nikele maruziyeti değerlendirmek için kantitatif testler de geliştirilmeye çalışılmıştır. Bunlardan birisi olan "acid wipe sampling" testinden, ilk defa 2010 yılında Jensen ve arkadaşlarının yaptığı pilot bir çalışmada bahsedilmektedir [33]. Bu çalışmada mesleksel nikel maruziyetini kantitatif olarak ölçmek için deride depolanan nikel miktarını değerlendirmek amaçlanmıştır. Ellerinde nikele bağlı mesleksel ekzeması ve yama testleri ile nikel allerjisi olduğu tespit edilen altı hasta çalışmaya dahil edilmiş, her bir hastanın sağ el işaret parmak ucu ön yüzüne, sağ el avuç içine ve kontrol alanı olarak sağ kol iç yüzüne $0,5 \mathrm{ml} \% 1$ nitrik asit emdirilmiş kağıt mendiller uygulanmıştır. Daha sonra bu kağıtlar bir dizi kimyasal teste tabii tutularak içlerindeki nikel konsantrasyonu belirlenmiştir. Bütün hastalarda en yüksek nikel konsantrasyonu işaret parmağında, ikinci sıklıkta avuç içi ve en az sıklıkta kontrol alanında tespit edilmiştir. Bu çalışma mesleği gereği nikele maruz kalan kişilerde derideki nikel birikimini kantitatif olarak belirlemenin diğer tanı testlerinden daha değerli olduğunu iddia etmektedir.

\section{Mesleksel nikel dermatiti}

\section{i.Tanı}

Türkiye'de meslek hastalığı tanısı Sosyal Sigortalar ve Genel Sağlık Sigortası Kanunu'nda belirtilen Çalışma Gücü ve Meslekte Kazanma Gücü Kaybı Oranı Tespit İşlemleri Yönetmeliği'ne dayanarak yapılabilmektedir. $\mathrm{Bu}$ kanunda meslek hastalığı "sigortalının çalıştığı veya yaptığ veya işin yürütüm şartları yüzünden uğradığı geçici veya sürekli hastalık, bedensel ve ruhsal özürlülük halleri”" olarak tanımlanmaktadır. Kanun gereği meslek hastalıkları hastaneleri, eğitim ve araştırma hastaneleri ve devlet üniversite hastanelerince oluşturulan sağlık kurulu raporu ile meslek hastalığı tanısı konulabilmektedir.

Diğer meslek hastalıklarında olduğu gibi nikele bağlı mesleksel kontakt dermatit tanısında öncelikle hastalığın mesleksel kaynaklı olup olmadığı ortaya konulmalıdır. Mesleksel kontakt dermatiti mesleksel olmayandan ayırt etmenin en önemli basamağı ayrıntılı bir meslek anamnezinin alınmasıdır. Özellikle lezyonların başlangıç yeri, işten uzaklaştırıldığında iyileşip iyileşmediği, iş yerinde diğer kişilerde görülüp görülmediği, iş yerinde maruz kaldığı malzemeler, atopi öyküsü, geçirilmiş kontakt dermatit öyküsü, bilinen alerjiler ve hobiler irdelenmelidir. Mathias kriterleri tanıya yardımcı olabilmektedir (Tablo IV) [34]. Yedi sorudan oluşan bu ankette dört soruya evet yanıtı mesleksel ilişkiyi doğrulamak için yeterlidir.

Toplumda nikel duyarlanmasının kulak deldirme ve benzeri nedenlerle çok yaygın görülmesi nedeniyle mesleksel kontakt dermatitin kesin olarak nikelden kaynaklandığını ortaya koymak her zaman mümkün olamamaktadır. İngiltere'de geniş kapsamlı çok merkezli bir çalışmada değişik meslek grubundan 547 mesleksel kontakt dermatit hastasından yama testi sonucu nikel için pozitif çıkmasına rağmen sadece \%36'sında nikelin etken sorumlu allerjen olduğu belirtilmektedir [35]. Bu nedenle mesleksel kontakt dermatit hastalarında bulunan nikel duyarlılığının rastlantısal $\mathrm{m} 1$ bulunduğu, yoksa dermatitden sorumlu faktör mü olduğunun ayırt edilmesi çok kolay değildir.

\section{ii. Klinik bulgular ve seyir}

Nikel dermatitinde metalin deriye direk kontaktı ile oluşan lezyonlar genellikle ekzematize bazen de papülerdir. Ekzemanın yerleşim yeri nikel ile direk temasın olduğu bölgeye göre değişkenlik gösterir. Nikele bağlı el ekzeması nikelle direk temas veya internal maruziyet ile meydana gelebilmektedir. Erkeklerde ellerdeki nikel dermatiti genellikle endüstriyel maruziyetledir (Şekil 1). İşçilerde prognoz, hijyenik önlemlere dikkat edildiğinde ve iş değişiklikleri yapıldığında daha iyidir. Kadınlarda kalitesiz mücevherler, yüzük, örgü şişleri veya nikel ile kaplanmış objelerin uzun süre teması ile nikel dermatiti gelişmektedir. Küpelere bağlı dermatitlerde kulak memesinde eritem, ödem, sulantı ve ekzematizasyon bulguları gözlenirken, kot pantolon düğmelerine bağlı dermatit göbek çevresine yerleşmeye eğilimli olup orta abdominal bölgenin büyük bir bölümünü de kaplayabilir. Bilezikler ve nikelle kaplı incik boncuk tarzı takıların ekzemaları el bileğinden ön kola ilerleyebilir. Eğer banyoda veya soyunurken çıkarılmazlarsa göğüste ve karında da döküntüye yol açabilirler [9]. 


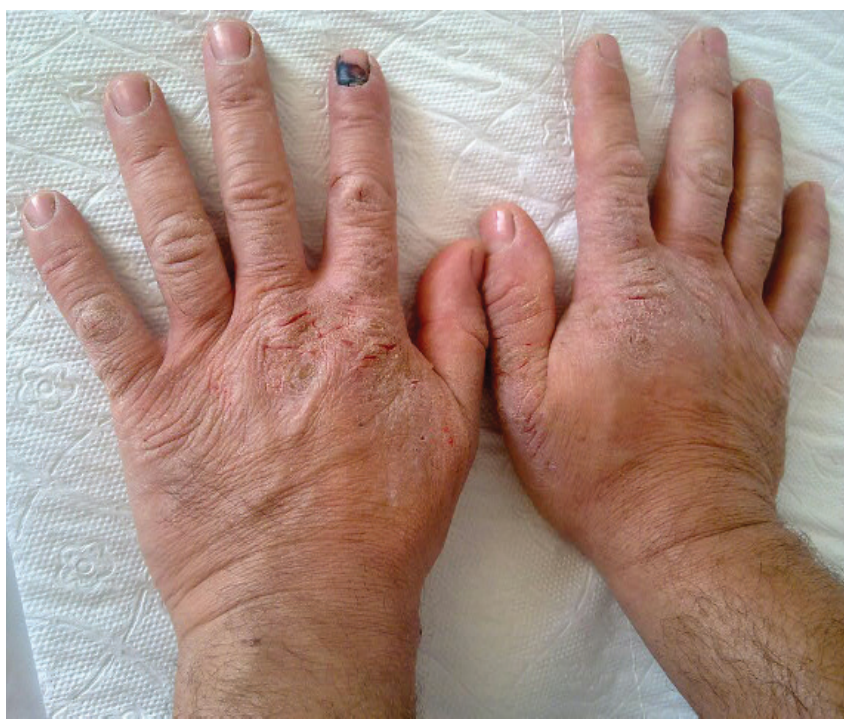

Şekil 1. 45 yaşındaki elektrik teknisyeninde nikel alerjisine bağlı ekzematöz görünüm.

Diyetteki nikel ile ilişkili dermatitleri inceleyen çalışmalarda, diyetteki nikelin lezyonların alevlenmesinde rolü olduğunu kanıtlayan bulgular ortaya konulmuştur. $\mathrm{Bu}$ kanitlar; ekzemalarda ve/veya yama test alanlarında oral nikel alımı ile alevlenme, diş teli takan çocuklarda düşük nikel içerikli diyet ile allerjik kontakt dermatit gelişiminde azalma, düşük nikel içeren diyetlerle ve oral disülfiram ile ekzemalarda düzelme (disülfiram nikel ile şelasyon yapar ve atılımını arttırır) olarak belirtilmektedir $[11,36]$.

\section{iii. Tedavi ve korunma}

Mesleksel nikel dermatitinde en önemli koruyucu tedavi prensibi nikele maruziyetin azaltılmasıdır. Bu sayede nikel duyarlılığ ve mesleksel kontakt dermatit görülme olasılığ 1 azaltılır. Mesleksel nikel dermatitinin sık görüldüğü kuaförler üzerinde yapılan bir çalışmada, konuyla ilgili bilgilendirici eğitim faaliyetleri sonrası koruyucu eldiven kullanma sıklığının arttığı ve bununla ilişkili olarak dermatit sıklığının azaldığı gösterilmiştir [37]. Kuzey Afrika metal rafinerisinde nikel üretim tanklarında çalışan işçiler üzerinde yapılan bir çalışmada ise deri hidrasyonu ve transepidermal su kaybının deriye etkileri araştırılmıştır. [38] Bu çalışmada her bir hastanın işaret parmağı, avuç içi, boyun ve alın bölgesinden özel mendiller ile alınan deri örnekleri plazma atomik emüsyon spektrometresi ile incelenmiştir. Hasarlanmış ve dehidrate deride nikelin permabilitesinin arttığı gösterilmiştir. Koruyucu eldivenlerin yetersizliğinin deride nikel birikimini artırdığı gözlenmiştir. $\mathrm{Bu}$ çalışmada tüm mesleksel nikel dermatit hastaları için geçerli olan bir dizi önlem önerilmiştir. $\mathrm{Bu}$ önlemler; koruyucu eldivenlerin hem mekanik hem kimyasal koruyucular içermesi, dimetilglioksim testi ile nikele maruz kalan alanların işe başlamadan önce belirlenmesi ve bu bölgelerin temizlenmesi ve uygun nemlendiriciler ile deri bakımının sağlanmasıdır.

Nikel duyarlılığı olan kişiler kullandıkları metal örgü şişleri, düğmeler, tokalar ve ofis malzemeleri gibi objeleri plastikleriyle değiştirmelidir. Benzer şekilde plastik tutacağ olan bardakları, plastik çerçeveli gözlükleri, alüminyum ya da teflondan yapılmış mutfak malzemeleri tercih etmelidirler. Devamlı metal obje ile teması olanlar temas yerlerine talk pudrası sürerek birkaç saatliğine cildi koruyabilirler. Talk pudrası hem mekanik bir bariyer oluşturur hem de metal objeden salınan nikelin bir kısmını absorbe eder. Koruyucu eldiven kullanımı durumunda vinil eldiven tercih edilmelidir. Nikel, lastik eldivenlerden geçebilirken, vinil olanlardan geçemez [39].

Nikel, krom ve kobalt ile beraber ortopedik protezlere olan duyarlanmanın en sık nedeni olup, yerleştirilen implantın başarısız olduğu olgularda normal popülasyonun altı katı sıklıkta metal duyarlanması olduğu belirtilmektedir. $\mathrm{Bu}$ nedenle, her ne kadar metal duyarlılığ protez operasyonları sonrası gelişen komplikasyon sıklı̆g 1 yüksek olmasa da operasyon öncesi yapılacak testlerle hasta için en uygun protezin seçilmesi önerilmektedir [40,41].

Nikel gündelik hayatta olduğu kadar çalışma hayatında sıkça maruz kalınan antijenlerden biridir. $\mathrm{Bu}$ nedenle mesleksel kontakt dermatit olgularında nikel maruziyeti mutlaka araştırılmalı ve altta yatan nedenin nikel olduğu olgularda koruyucu önlemlerin (uygun eldiven ile ellerin korunması, sık tekrarlıyorsa iş değişikliği gibi) alınması önemlidir.

\section{Kaynaklar}

1. Clark SC, Zirwas MJ. Management of occupational dermatitis. Clin Dermatol 2009; 27:365-83. doi: 10.1016/j.det.2009.05.002

2. Nixon R, Frowen K, Moyle M. Occupational dermatoses. Aust Fam Physician 2005; 34:327-33.

3. Johansen JD, Menné T, Christophersen J, Kaaber K, Veien N. Changes in the pattern of sensitization to common contact allergens in Denmark between 1985-86 and 1997-98, with a special view to the effect of preventive strategies. Br J Dermatol 2000; 142:490-5. doi: 10.1046/j.1365-2133.2000.03362.x

4. Marks JG, Belsito DV, DeLeo VA, et al. North American Contact Dermatitis Group patch test results for the detection of delayed-type hypersensitivity to topical allergens. J Am Acad Dermatol 1998; 38:911-8. doi: 10.1016/S0190-9622(98)70587-0

5. Sertoli A, Francalanci S, Acciai MC, Gola M. Epidemiological survey of contact dermatitis in Italy (1984-1993) by GIRDCA. Am J Contact Dermat 1999; 10:18-30. doi: 10.1016/S1046-199X(99)90089-1

6. Uter W, Schnuch A, Geier J, Frosch P. Epidemiology of contact dermatitis. The Information Network of Departments of Dermatology. Eur J Dermatol 1998; 1:36-40.

7. Erdem T, Kılıç B. Dermatolojide nikel alerjisi. Turkiye Klinikleri J Dermatol- Special Topics 2012;5:31-7.

8. Fransway AF, Zug KA, Belsito DV, et al. North American Contact Dermatitis Group patch test results for 2007 - 2008. Dermatitis 2013; 24:10-21. doi: 10.1097/DER0b013e318277ca50. 
9. Rietschel RL, Fowler JF. Metals. In: Rietschel RL, Fowler JF Jr, eds. Fisher's Contact Dermatitis. 6th ed. Hamilton: BC Decker Inc, 2008: 641-81.

10. Boyvat A, Akyol A. Allerjik kontakt dermatitli olgularda yama testi sonuçları. T Klin Alerji Astım 2000; 2:156-67.

11. Sharma AD. Relationship between nickel allergy and diet. Indian J Dermatol Venereol Leprol 2007; 73:307-12. doi: 10.4103/03786323.35733

12. Goh CL. Common industrial processes and occupational irritants and allergens-an update. Ann Acad Med Singapore 1994; 23:690-8.

13. Salazar LC, Guimaraens D, Villegas C, Romero A, Gonzalez MA. Occupational allergic contact dermatitis in construction workers. Contact Dermatitis 1995; 33:226-30.

14. Jue MS, Kim YS, Ro YS. Fiddler's neck accompanied by allergic contact dermatitis to nickel in a viola player. Ann Dermatol 2010; 22:88-90.

15. Wallenhammer LM, Ortengren U, Andreasson H, et al. Contact allergy and hand eczema in Swedish dentists. Contact Dermatitis 2000; 43:192-9. doi: 10.1034/j.1600-0536.2000.043004192.x

16. Duarte I, Rotter A, Lazzarini R. Frequency of occupational contact dermatitis in an ambulatory of dermatologic allergy. An Bras Dermatol 2010; 85:455-9.

17. Brandao MH, Gontijo B, Girundi MA, de Castro MC. Ear piercing as a risk factor for contact allergy to nickel. J Pediatr (Rio J) 2010; 86:149-54.

18. Shiao JS, Sheu HM, Chen CJ, Tsai PJ, Guo YL. Prevalence and risk factors of occupational hand dermatoses in electronics workers. Toxicol Ind Health 2004; 20 :1-7. doi: 10.1191/0748233704th193oa

19. Krecisz B, Kiec-Swierczynska M, Chomiczewska D. Dermatological screening and results of patch testing among Polish apprentice hairdressers. Contact Dermatitis 2011; 64:90-5. doi: 10.1111/j.16000536.2010.01844.x

20. Bordel-Gómez MT, Miranda-Romero A, Castrodeza-Sanz J. Epidemiology of contact dermatitis: prevalence of sensitization to different allergens and associated factors. Actas Dermosifiliogr 2010; 101:59-75. doi: 10.1016/S1578-2190(10)70581-3

21. Whörl S, Jandl T, Stingl G, Kinaciyan T. Mobile telephone as new source for nickel dermatitis. Contact Dermatitis 2007;56:113. doi: 10.1111/j.1600-0536.2007.00296.x

22. Thyssen JP, Johansen JD, Menné T, Nielsen NH, Linneberg A. Effect of tobacco smoking and alcohol consumption on the prevalence of nickel sensitization and contact sensitization. Acta Derm Venereol 2010; 90:27-33. doi: 10.2340/00015555-0772

23. Akasya E, Bayazıt EÖ. Avrupa standart yama testi serisi. Turkderm 2001; 35:265-76.

24. Minang JT, Areström I, Troye-Blomberg M, Lundeberg L, Ahlborg N. Nickel, cobalt, chromium, palladium and gold induce a mixed Th1- and Th2-type cytokine response in vitro in subjects with contact allergy to the respective metals. Clin Exp Immunol 2006; 146:417-26. doi: $10.1111 /$ j.1365-2249.2006.03226.x

25. Young E, Honwing RH. Patch test results with standart allergens over a decade. Contact Dermatitis 1987; 17:104-7. doi: 10.1111/j.16000536.1987.tb02670.x
26. Menné T, Dooms-Goossens A, Wahlberg JE, White IR, Shaw S. How large a population of contact sensitivities are diagnosed with the European Standard Series? Contact Dermatitis 1992; 26:201-2.

27. Nonaka H, Nakada T, Ijima M, Howard I. Metal patch test results from 1990-2009. J Dermatol 2011; 38:267-71. doi: 10.1111/j.13468138.2010.00980.x

28. Akyol A, Gürgey E, Erdi H, Taşpınar A. Evaluation of the patch test results with standard antigens in various types of eczema. Contact Dermatitis 1996; 35:303. doi: 10.1111/j.1600-0536.1996.tb02394.x

29. Akasya-Hillenbrand E, Özkaya-Beyazıt E. Patch test results in 542 patients with suspected contact dermatitis in Turkey. Contact Dermatitis 2002; 46:17-23. doi: 10.1034/j.1600-0536.2002.460104.x

30. Ada S. Allerjik kontakt dermatitli 775 olgunun yama testi sonuçları. Turkderm 2010; 44:187-92.

31. Gündüz Ö, Aytekin A, Yılmaz H. Meslek Hastalıkları Hastanesi'nde 231 hastaya uygulanan deri yama testi sonuçlarının değerlendirilmesi. E-Poster bildiri. 1.Ulusal Mesleki Deri Hastalıkları Sempozyumu 23 -27 Mart 2011 Erzurum

32. Shore RN, Binnick S. Dimethylglioxime stick test for easier detection of nickel. Arch Dermatol 1977; 113:1734. doi: 10.1001/ archderm.1977.01640120102043

33. Jensen P, Thyssen JP, Johansen JD, Skare L, Menné T, Lidén C. Occupational hand eczema caused by nickel and evaluated by quantitative exposure assessment. Contact Dermatitis 2011; 64:32-6. doi: 10.1111/j.1600-0536.2010.01819.x

34. Mathias CG. Contact dermatitis and worker's compensation: criteria for establishing occupational causation aggravation. J Am Acad Dermatol 1989; 20 (5 Pt 1):842-8.

35. Shum K, Meyer J, Chen Y, Cherry N, Gawkrodger D. Occupational contact dermatitis to nickel: experience of British dermatologists (EPIDERM) and occupational physicians (OPRA) surveillance schemes. Occup Environ Med 2003; 60:954-7. doi: 10.1136/ oem.60.12.954

36. Zirwas MJ, Molenda MA. Dietary nickel as a cause of systemic contact dermatitis. J Clin Aesthet Dermatol 2009; 2:39-43.

37. Bregnhoj A, Menne T, Johansen JD, Sosted H. Prevention of hand eczema among Danish hairdressing apprentices: an intervention study. Occup Environ Med 2012; 69:310-6. doi: 10.1136/ oemed-2011-100294.

38. Du Plessis JL, Eloff FC, Badenhorst CJ, et al. Assessment of dermal exposure and skin condition of workers exposed to nickel at a South African base metal refinery. Ann Occupy Hyg 2010; 54:23-30 doi: 10.1093/annhyg/mep080

39. Wall LM. Nickel penetration through rubber gloves. Contact Dermatitis 1980; 6:461-3. doi: 10.1111/j.1600-0536.1980.tb05566.x

40. Frigerio E, Paolo D. Pigatto PD, Guzzi G, Altomare G. Metal sensitivity in patients with orthopaedic implants: a prospective study. Contact Dermatitis 2011; 64:273-9.

41. Hallab N, Merritt K, Jacobs J J. Metal sensitivity in patients with orthopaedic implants. J Bone Joint Surg Am 2001; 83: 428-36. 